\title{
ESS \\ PEM Fuel Cell Start-Up/Shut-Down Losses vs Relative Humidity: The Impact of Water in the Electrode Layer on Carbon Corrosion
}

\author{
Thomas Mittermeier, (1)*,a,z Alexandra Weiß, ${ }^{* *}$ Frédéric Hasché, and Hubert A. Gasteiger*** \\ Chair of Technical Electrochemistry, Department of Chemistry and Catalysis Research Center, Technical University of \\ Munich, D-85748 Garching, Germany
}

For automotive applications, one of the main challenges for proton exchange membrane fuel cells (PEMFCs) is to increase the lifetime of membrane electrode assemblies (MEAs), especially during transient operating conditions such as start-up/shut-down (SUSD) cycles. During SUSD, the carbon support in the cathode layer is known to be oxidized as a consequence of hydrogen/air ${ }_{\text {anode }}$ gas fronts moving through the anode. In this work, we focus on the effect of relative humidity (RH) during SUSD events. Here we show the significant impact on PEMFC performance by both experiments with $50 \mathrm{~cm}^{2}$ single-cell PEMFCs and by a simple SUSD model using the RH-dependent kinetics for the carbon oxidation reaction (COR) rate. The kinetic parameters of the COR are determined by on-line mass spectrometry, yielding a COR reaction order with respect to RH of one. Utilizing the thus determined COR kinetics in the SUSD model predicts $\mathrm{a} \approx 3$-fold lower COR during SUSD events at $80^{\circ} \mathrm{C}$ for an $\mathrm{MEA}$ with a conventional high surface area carbon support when the $\mathrm{RH}$ is decreased from $100 \%$ to $25 \%$. This agrees perfectly well with the experimentally determined factor of $\approx 3$.

(C) The Author(s) 2018. Published by ECS. This is an open access article distributed under the terms of the Creative Commons Attribution Non-Commercial No Derivatives 4.0 License (CC BY-NC-ND, http://creativecommons.org/licenses/by-nc-nd/4.0/), which permits non-commercial reuse, distribution, and reproduction in any medium, provided the original work is not changed in any way and is properly cited. For permission for commercial reuse, please email: oa@electrochem.org. [DOI: 10.1149/2.0931816jes]

(cc) BY-NC-ND

Manuscript submitted October 11, 2018; revised manuscript received December 6, 2018. Published December 22, 2018.

The U.S. Department of Energy (DoE) and the Environmental Protection Agency (EPA) show that the driving ranges of current (Oct. 2018) commercial fuel cell electric vehicles (FCEVs) are between $265-378$ miles $(\approx 426-609 \mathrm{~km}){ }^{1,2}$ Such driving ranges, comparable to those achieved with conventional combustion engine cars, in combination with short hydrogen re-fueling times of $\approx 3$ minutes, ${ }^{3}$ spare the need to adapt customer habits in a transitional market from conventional to fuel cell electric vehicles. However, the FCEV sales figures of major OEMs are still negligibly small compared to their overall vehicle sales. ${ }^{4}$ To successfully reach the commercial mass production phase for proton exchange membrane fuel cell (PEMFC) powered light duty FCEVs, the DoE has identified six major requirement targets for 2020 , comprising peak energy efficiency, power density, specific power, freeze-start capability, cost reduction, and durability. ${ }^{5}$ While the prior four targets have already been achieved or are close to their target values $(>90 \%)^{5}$, the current cost of $\approx 53 \$ \cdot \mathrm{kW}^{-1}$ net electrical power compared to the target of $30 \$ \cdot \mathrm{kW}^{-1}$ is still a major hurdle. A comprehensive projection of cost reduction associated with mass-market introduction of FCEVs was given by Gröger et al. ${ }^{6}$ and is not subject of the current work. The second major issue is PEMFC durability. While $3930 \mathrm{~h}$ out of the targeted $5000 \mathrm{~h}$ operation with a tolerable performance loss $<10 \%$ have already been demonstrated, ${ }^{7}$ transient operation modes such as start-up/shut-down (SUSD) lack demonstrated robustness.

An SUSD event as described by Reiser's "reverse-current decay mechanism" occurs when a hydrogen/air anode $_{\text {gas }}$ front passes the anode flow-field of a fuel cell. ${ }^{8}$ It is known to invoke oxidative currents on the cathode electrode, which primarily damage the cathode catalyst carbon support. This damage due to carbon support corrosion is significantly lower at low temperatures and when graphitized carbon supports are used for the cathode catalyst; in this case, the performance degradation caused by SUSD events is predominantly due to platinum surface area loss. ${ }^{9}$ Early demands for tolerance against SUSD events were as high as 38,500 times at $80^{\circ} \mathrm{C}$ over vehicle life, as they were based simply on the average number of vehicle startups. ${ }^{10}$ Owing to the fact that damaging SUSD events (i.e., those where a

\footnotetext{
*Electrochemical Society Member.

**Electrochemical Society Student Member.

***Electrochemical Society Fellow.

apresent address: BMW Group, D-80788 Munich, Germany.

${ }^{\mathrm{z}}$ E-mail: thomas.mittermeier@tum.de
}

hydrogen/air ${ }_{\text {anode }}$ gas front occurs) have been decreased by maintaining the stack under $\mathrm{H}_{2}$ for an extended time after shutdown, ${ }^{11,12}$ the 2020 DoE target has been reduced to a number of 5,000 SUSD events.

Other than the temperature at which an SUSD event takes place, the second major operational parameter affecting the carbon oxidation reaction (COR) rate is the relative humidity $(\mathrm{RH})$. This parameter is directly linked to the water content of the membrane and the ionomer in the catalyst layer of a membrane electrode assembly (MEA). Lim et al. indirectly tested the $\mathrm{RH}$ dependence of the carbon corrosion rate by performing carbon corrosion experiments at $1.4 \mathrm{~V}$ vs. RHE (reversible hydrogen electrode potential) at different temperatures while keeping the water vapor partial pressure constant. ${ }^{13}$ Experimental single-cell based SUSD studies by Kreitmeier et al. and Ofstad et al. investigated the effect of the variation of $\mathrm{RH}$ at $80^{\circ} \mathrm{C}$, both studies showing a positive correlation of the $\mathrm{COR}$ and the $\mathrm{RH}$ deduced from on-line $\mathrm{CO}_{2}$ measurements. ${ }^{14,15}$ However, the PEMFC performance decay upon subsequent SUSD cycles was not measured in these studies. Gu et al. ${ }^{16,17}$ developed a kinetic model to semi-quantitatively predict damage due to SUSD with which they predicted the relative change of the COR rate for different cathode catalyst carbon support types. Only more recently, the experimentally determined PEMFC performance loss over extended SUSD cycles was combined with a prediction of the COR rate at different temperatures and for different carbon supports. ${ }^{9}$ To the best of our knowledge, no models predicting the $\mathrm{RH}$-dependence of $\mathrm{H}_{2} /$ air ${ }_{\text {anode }}$ front induced SUSD events have been published so far, which is likely due to the lack of published kinetic data on the reaction order to the COR with respect to RH. ${ }^{10,17-19}$ While there are experimental studies published focusing on the performance decay during SUSD cycles under various RH conditions (e.g., Kim et al.), ${ }^{20}$ a rigorous study with unmitigated $\mathrm{H}_{2} /$ air $_{\text {anode }}$ gas fronts is yet outstanding.

Therefore, this study focuses on the prediction and experimental determination of the SUSD damage induced by extended $\mathrm{H}_{2} /$ air $\mathrm{anode}_{\text {and }}$ gas fronts passing through $50 \mathrm{~cm}^{2}$ single-cell PEMFCs as a function of RH. In order to determine the COR reaction order with respect to $\mathrm{RH}$ (or water partial pressure), the COR rate at $80^{\circ} \mathrm{C}$ vs. potential and RH was quantified by on-line mass spectrometry. For all experiments, commercial catalyst coated membranes (CCMs) with catalyst supported on high surface area carbon were used and their material specific properties were utilized in the SUSD model in order to predict the COR rates during SUSD events. 


\section{Experimental}

Hardware, set-up and materials.-For SUSD experiments, the materials and devices used were the same as in our previous publication. ${ }^{9}$ In short, single-cell PEMFC experiments were carried out on a customized G60 test station (Greenlight Innovation Corp.) using a $50 \mathrm{~cm}^{2}$ cell hardware with quadruple-serpentine flow-fields (Fuel Cell Technologies, Inc.). Commercial CCMs (Primea Mesga A510.1/M715.18/C580.4, W. L. Gore $\mathrm{GmbH}$ ) with catalysts based on a high surface area carbon support and applied at loadings of $0.1 / 0.4 \mathrm{mg}_{\mathrm{Pt}} \cdot \mathrm{cm}^{-2}$ (anode/cathode) were sandwiched in between two SIGRACET 25BC (SGL Carbon $\mathrm{GmbH}$ ) gas diffusion layers (GDLs). Proper compression and sealing were assured via nearly incompressible PTFE coated glassfiber gaskets (Fiberflon $\mathrm{GmbH}$ ) chosen the appropriate thickness to result in a ca. 20\% compression of the GDLs, corresponding to $\approx 1.5 \mathrm{MPa}$ compression pressure on the flow-field lands. ${ }^{21}$ Sharp $\mathrm{H}_{2} /$ air $_{\text {anode }}$ gas fronts with a residence time of $1.3 \mathrm{~s}$ were generated utilizing an additional anode humidifier and an appropriate valve switching mechanism as described before. ${ }^{9}$

COR experiments were carried out using the same materials, but in order to avoid in-plane diffusion of $\mathrm{CO}_{2}$ from the ambient through the PTFE coated fiberglass gaskets toward the active cell area, which would lead to erroneous gas analysis, virgin PTFE gaskets were used instead. The exhaust gas was analyzed on-line with a Cirrus 3-XD mass spectrometer system (MKS Instruments Deutschland GmbH), equipped with Thoria filaments in an enclosed ion source, using an offaxis secondary electron multiplier. The gas was sampled via a stainless steel capillary heated to $150^{\circ} \mathrm{C}$, allowing for a gas flow equivalent of $\approx 6 \mathrm{nccm}$ at ambient inlet pressure toward the recipient (controlled at $\approx 10$ mbar via a dynamic bypass). An orifice array of five $15 \mu \mathrm{m}$ holes separated the ion source $\left(\approx 5 \cdot 10^{-3}\right.$ mbar $)$ from the recipient and the pressure in the analyzer was maintained at $\approx 10^{-5}$ mbar by a turbomolecular pump. The capillary was mounted into the center of the PEMFC gas exhaust via a Swagelok T-connection, while the piping between the fuel cell hardware and the capillary was kept at a minimum length and heated externally to $\approx 120^{\circ} \mathrm{C}$ via a heating rope (Horst $\mathrm{GmbH}$ ) in order to avoid condensation of water.

MEA conditioning.-All MEAs used in this study were conditioned before conducting either SUSD or COR experiments via a sequence of potentiostatic steps under $\mathrm{H}_{2}$ (1400 nccm on the anode) and air (3300 nccm on the cathode); note that normal cubic centimeters per minute $(\mathrm{nccm})$ are referenced to $\mathrm{T}_{0}=273.15 \mathrm{~K}$ and $\mathrm{p}_{0}=$ $101.3 \mathrm{kPa}$. Hereby, temperature and pressure were controlled at $60^{\circ} \mathrm{C}$ and $50 \mathrm{kPa}_{\text {gauge, inlet }}$, respectively, with the reactants humidified at $60^{\circ} \mathrm{C}$ dew point (i.e., at $\mathrm{RH}=1.0$ whereby $\mathrm{RH}$ is defined throughout this work as fraction rather than as percentage). Eight subsequent cycles of the following steps were performed: i) $0.60 \mathrm{~V}$ for $45 \mathrm{~min}$, ii) $0.95 \mathrm{~V}$ for $5 \mathrm{~min}$, and iii) $0.85 \mathrm{~V}$ for $10 \mathrm{~min}$.

SUSD experiments.-Polarization curves were taken directly after MEA conditioning and after every set of 10 SUSD cycles in order to monitor voltage losses at reference conditions of $80^{\circ} \mathrm{C}$, inlet pressure of $70 \mathrm{kPa}_{\text {gauge,inlet }}$ (both anode and cathode), inlet relative humidities of $\mathrm{RH}=0.66$, and stoichiometries of $1.5_{\mathrm{H} 2} / 1.8_{\text {air }}$. Below $0.2 \mathrm{~A} \cdot \mathrm{cm}^{-2}$, gas flows were kept constant at the stoichiometric flow corresponding to $0.2 \mathrm{~A} \cdot \mathrm{cm}^{-2}$. Prior to each polarization curve, a potentiostatic recovery step with the electric load controlled at $0.60 \mathrm{~V}$ (at above described conditions) was applied for $2 \mathrm{~min}$. Subsequently, the polarization curve was recorded in current-control mode (i.e., galvanostatically) from low to high current densities, whereby each current step was held for $6 \mathrm{~min}$ of which the last $10 \mathrm{~s}$ were averaged for each data point. The thus obtained polarization curves were used to determine time-normalized degradation rates (i.e., normalized to the residence time of the $\mathrm{H}_{2} /$ air $_{\text {anode }}$ gas front during SUSD cycles), as described previously. 9

SUSD cycling was done for RH values between $0.25-1.20$ at $80^{\circ} \mathrm{C}$ cell temperature, whereby the inlet dry gas partial pressure (on both anode and cathode) was kept constant at $\approx 101 \mathrm{kPa}_{\text {abs }}$, resulting in total

\begin{tabular}{|c|c|c|c|c|c|c|c|c|c|c|}
\hline Step & 1 & 2 & 3 & 4 & 5 & 6 & 7 & 8 & 9 & 10 \\
\hline Dwell time [min] & 1 & 5 & 5 & 1 & 1 & 1 & 1 & 1 & 1 & 2 \\
\hline Ar flow [nccm] & 80 & 600 & 4000 & 800 & 80 & 4000 & 800 & 80 & 4000 & 600 \\
\hline
\end{tabular}

inlet pressures in the range of $12-47 \mathrm{kPa}_{\text {gauge, inlet }}$ (no further correction for actual absolute ambient pressure was applied). At constant dry gas pressure and applied gas flow rates of $113 \mathrm{nccm}\left(\mathrm{H}_{2}\right.$ or air on the anode and air on the cathode), the $\mathrm{H}_{2} /$ air $_{\text {anode }}$ gas front residence time was $\approx 1.3 \mathrm{~s}$ in all experiments (cf., Equation 20 in our previous publication), ${ }^{9}$ and the dwell time in between gas fronts was $120 \mathrm{~s}$ in all cases. Note that one SUSD cycle in this work refers to the combination of one shut-down and one start-up event.

Quantification of the COR rate via mass spectrometry.-All ion currents recorded were normalized to the $\mathrm{m} / \mathrm{z}=36$ signal corresponding to the natural ${ }^{36} \mathrm{Ar}$ isotope in the argon (Ar) carrier gas (5.0 grade, Westfalen AG) in order to minimize potential atmospheric disturbances (e.g., pressure fluctuation resulting from the backpressure valve of the test station). Prior to each carbon corrosion experiment, the $\mathrm{m} / \mathrm{z}=44$ signal of the mass spectrometer (corresponding to $\mathrm{CO}_{2}$ ) was calibrated with the pre-conditioned fuel cell attached and at the conditions of interest (i.e., RH chosen between $0.20-1.00$ and total pressure adjusted such as to yield a dry gas pressure of $\approx 101 \mathrm{kPa}_{\mathrm{abs}}$ ). The calibration gas (1000 ppm $\mathrm{CO}_{2}$ in Ar 5.0, Westfalen AG) was mixed with Ar carrier gas via the mass flow controllers of the fuel cell test station at different ratios $(0 \%, 25 \%, 50 \%, 75 \%, 100 \%)$ and at a total flow rate of $\approx 80 \mathrm{nccm}$. During calibration, the anode flow-field (serving as counter and reference electrode) was kept under a constant flow of $200 \mathrm{nccm}$ of $5 \% \mathrm{H}_{2}$ in $\mathrm{N}_{2}$ and the cell was left at its open circuit voltage. After the calibration, remnants of $\mathrm{CO}_{2}$ were removed from the test station's gas and the humidification system by purging with Ar for ca. 20 min (details see Table I). Subsequently, the Ar flow was set to $80 \mathrm{nccm}$ and the whole experimental set-up was equilibrated for $\geq 1 \mathrm{~h}$, before a potential of $0.50 \mathrm{~V}_{\mathrm{RHE}}$ was applied to the cathode flow-field (working electrode) via a potentiostat (Gamry Instruments) for $15 \mathrm{~min}$. Note that the applied potential was corrected for $101 \mathrm{kPa}$ $\mathrm{H}_{2}$ partial pressure using the Nernst equation, so that $0 \mathrm{~V}_{\mathrm{RHE}}$ refer to the potential which would be measured under pure $\mathrm{H}_{2}$. Subsequently, the working electrode potential was increased in steps of $0.05 \mathrm{~V}$ every $30 \mathrm{~s}$ until $1.50 \mathrm{~V}_{\mathrm{RHE}}$, while recording the ${ }^{36} \mathrm{Ar}$ normalized $\mathrm{CO}_{2}$ signal continuously. The data were analyzed by applying the previously obtained linear calibration curve to the measured ${ }^{36} \mathrm{Ar}$ normalized ion current.

Kinetic $\mathrm{H}_{2} /$ Air ${ }_{\text {anode }}$ SUSD model description.-In a previous publication, our group utilized a quasi-steady-state one-dimensional kinetic model originally developed by $\mathrm{Gu}$ et al. ${ }^{17}$ to predict carbon corrosion currents during SUSD events for CCMs with graphitized or with non-graphitized carbon supports. ${ }^{9}$ That study focused on the temperature dependence of the SUSD induced carbon corrosion current and the resulting fuel cell performance loss, whereby the relative humidity was kept at $\mathrm{RH} \geq 1.0 .^{9}$ In the present study, the $\mathrm{RH}$ at which the $\mathrm{H}_{2} /$ air $_{\text {anode }}$ gas fronts are purged through the single-cell PEMFC is varied between $\mathrm{RH}=1.00$ (fully humidified) and 0.25 while keeping a constant temperature of $80^{\circ} \mathrm{C}$. In order to adapt our previously described SUSD model ${ }^{9}$ to different $\mathrm{RH}$ values, it has to be extended for the carbon oxidation reaction order with respect to reactant water activity $\left(\gamma_{\mathrm{COR}}\right)$.

Since the carbon support surface in the catalyst layer is generally assumed to be covered by ionomer, the COR is expected to occur at the carbon/ionomer interface, i.e., the water required for the COR should be supplied from the ionomer phase rather than from the gas phase. 
Consequently, the activity of water at the reaction interface should correspond to the water activity within the ionomer $\mathrm{a}_{\mathrm{H} 2 \mathrm{O}, \text { Ionomer }}$ (here assumed to be isotropic due to the low current densities during SUSD). While the water uptake of $\mu \mathrm{m}$-sized ionomeric membranes such as Nafion is well known, it was shown that nm-thin ionomer films exhibit significantly different water uptake characteristics (unfortunately, the actual trends are unclear, as in some studies the water uptake for thin films is increased, ${ }^{22}$ while in others it is reduced). ${ }^{23}$ Taking into account the imperfect ionomer surface in such thin films, a study conducted by Nissan (Iden et al.) ${ }^{24}$ determined the RH-dependence of the water uptake of the ionomer in pseudo-catalyst layers comprising of Ketjenblack and ionomer at various ionomer to carbon ratios (cf., their Figure 11a). As a result, they found a very linear correlation between uptake and $\mathrm{RH}$ (a linear fit results in $\mathrm{R}^{2} \approx 0.96$ for $0.2 \leq \mathrm{RH}$ $\leq 0.95$ ), whereby the water uptake of the ionomer in their pseudocatalyst layers always remained below that of $\mu \mathrm{m}$-sized ionomer films. These results presented by Iden et al. on pseudo-catalyst layers show good agreement with the work conducted by Kusoglu et al., ${ }^{23}$ where the water uptake in thin ionomer layers ( $156 \mathrm{~nm}-11 \mathrm{~nm})$ supported on a planar substrate was measured using a quartz crystal microbalance: with lower thickness, the trend of water uptake vs. RH transformed from that resembling a bulk ionomeric membrane toward a linear behavior (cf., Figure $5 b$ in Kusoglu et al.). ${ }^{23}$

Based on these data, a linear trend of the water uptake vs. RH implies that the activity of water in the ionomer phase $\mathrm{a}_{\mathrm{H} 2 \mathrm{O} \text {,Ionomer }}$ at a constant temperature should be proportional to $\mathrm{RH}$, i.e., $\mathrm{a}_{\mathrm{H} 2 \mathrm{O} \text {,Ionomer }} \propto$ $\mathrm{RH}$. Therefore, in the following, the COR rate will be considered to be directly dependent on $\mathrm{RH}$, so that the exchange current density of the $\mathrm{COR}$ at any $\mathrm{RH}\left(\mathrm{i}_{0, \mathrm{COR}}\right)$ can be expressed by multiplying the exchange current density at $\mathrm{RH}=1\left(\mathrm{i}_{00, \mathrm{COR}}\right)$ with a reaction order $\gamma_{\mathrm{COR}}$ written in terms of $\mathrm{RH}$ :

$$
\mathrm{i}_{0, \mathrm{COR}}=\mathrm{i}_{00, \mathrm{COR}} \cdot \mathrm{RH}^{\gamma \mathrm{COR}}
$$

Clearly, when considering values of $\mathrm{RH} \leq 1$ only (i.e., gas phase water), which is done in this study, Equation 1 could as well be expressed as a function of water vapor pressure, as was suggested by Gallagher and Fuller. ${ }^{25}$ For the present study, a further Arrhenius correction to $\mathrm{i}_{00, \mathrm{COR}}$ was not necessary, as all experiments were carried out at the temperature of $80^{\circ} \mathrm{C}$, to which $\mathrm{i}_{00, \mathrm{COR}}$ is referred. ${ }^{9,17}$ In the fuel cell literature, some hints about the magnitude of $\gamma_{\mathrm{COR}}$ can be found, ${ }^{13,14,26}$ even though these experiments do not explicitly quantify the COR kinetics and specifically $\gamma_{\mathrm{COR}}$ under controlled reaction conditions. It should be pointed out that studies of the COR in concentrated phosphoric acid (A. J. Appleby) ${ }^{27}$ and half-cell PEMFCs (Maass et al. $)^{28}$ point toward a reaction order for the COR of unity with respect to water vapor pressure, as already summarized by Gallagher and Fuller. ${ }^{25}$ However, first Appleby's study in concentrated phosphoric acid shows that $\gamma_{\mathrm{COR}}$ can be different for different concentration ranges of phosphoric acid, which renders it necessary to explicitly demonstrate $\gamma_{\mathrm{COR}}$ in the relevant low-temperature PEMFC environment. Second, Maass' study does evaluate the impact of water vapor pressure on COR in PEMFC half-cell experiments purely from an electrochemical standpoint, so that a direct detection of $\mathrm{CO}_{2}$ as the most prominent reaction product, e.g., via mass spectrometry is yet missing in an experimental work. Thus, we examined four different scenarios with $\gamma_{\mathrm{COR}}=0,0.5,1$, or 2 for our SUSD model.

The model comprises the following steps: First, the internal total current flowing through the fuel cell during an SUSD event ISUSD, the corresponding cell voltage, and the associated local half-cell potentials were calculated. From these, the fractions of ISUSD consumed by the oxygen evolution $\mathrm{i}_{\mathrm{OER}}^{\text {cathode }}$ and the carbon oxidation reaction $\mathrm{i}_{\text {COR }}^{\text {cathode }}$ occurring on the cathode electrode were determined, yielding $\chi_{\mathrm{COR}}$ :

$$
\chi_{\mathrm{COR}}=\frac{\mathrm{i}_{\mathrm{COR}}^{\text {cathode }}}{\mathrm{i}_{\mathrm{COR}}^{\text {cathode }}+\mathrm{i}_{\mathrm{OER}}^{\text {cathode }}}
$$

All further equations used in the model of this study are identical with those given in our previous publication; ${ }^{9}$ the required physicalchemical parameters are those from Tables I and II specified for "conventional C MEAs" in Reference 9, unless stated otherwise (note that in Table II of Reference 9, $\mathrm{i}_{00}$ for the COR was mistakenly given in units of $\mathrm{A} \cdot \mathrm{cm}_{\mathrm{Pt}}^{-2}$ rather than in $\mathrm{A} \cdot \mathrm{cm}_{\mathrm{C}}^{-2}$ and that $\alpha_{\mathrm{C}}$ should have been labelled $\alpha_{\mathrm{A}}$ ).

Figure 1 shows the projected COR current densities during SUSD for the materials used in the SUSD experiments. The calculations are based on assumed values of $\gamma_{\mathrm{COR}}=0,1$ and $2\left(\gamma_{\mathrm{COR}}=0.5\right.$ not shown $)$ as a function of the relative $\mathrm{H}_{2} /$ air $_{\text {anode }}$ front position $\left(\mathrm{H}_{2} /\right.$ air $\mathrm{r}_{\text {anode }}=0$ means the entire anode flow-field is under air, $\mathrm{H}_{2} /$ air $_{\text {anode }}=1$ means the entire anode flow-field is under $\mathrm{H}_{2}$ ) and as a function of relative humidity. In accordance with Equation 1, the COR current densities at $\mathrm{RH}=1$ shown in Figures $1 \mathrm{a}), 1 \mathrm{~b}$ ) and 1c) are identical; at lower RH values, the COR rates decrease the more, the higher the reaction order $\gamma_{\mathrm{COR}}$ with respect to RH (or water activity). That a decrease of
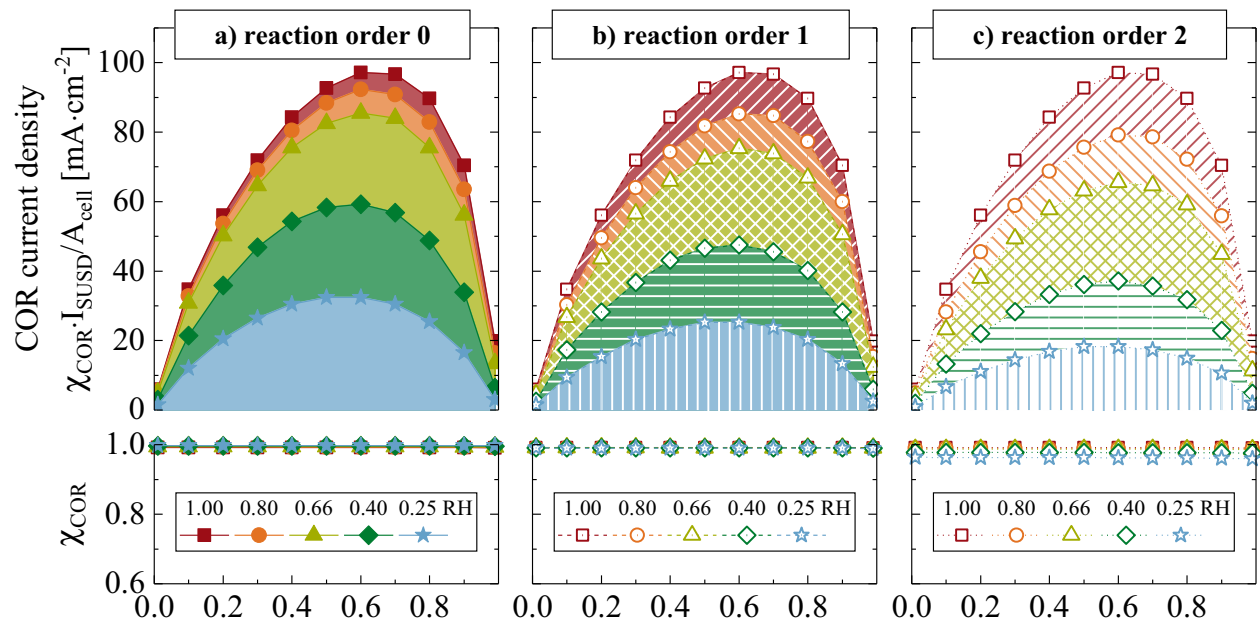

relative $\mathrm{H}_{2} /$ air $_{\text {anode }}$ front position $\tau$

Figure 1. Upper panel: Calculated carbon oxidation reaction (COR) current densities averaged over the cathode active area for SUSD events at relative humidities from 0.25-1.00 (see legend in lower panels) versus relative $\mathrm{H}_{2} /$ air anode front position ( $\tau=0$ means that the entire anode flow-field is filled with air; $\tau=1$ means that the entire anode flow-field is filled with $\mathrm{H}_{2}$ ), assuming a COR reaction order with respect to $\mathrm{RH}$ (see Equation 1 ) of a) $\left.\chi_{\mathrm{COR}}=0, \mathrm{~b}\right) \chi_{\mathrm{COR}}=1$, and $\mathrm{c}$ ) $\chi_{\mathrm{COR}}=$ 2. Lower panel: Fractions of the SUSD current consumed by the COR ( $\chi_{\mathrm{COR}}$; see Equation 2$)$ for each assumed COR reaction order. All other physical-chemical parameters are those from Tables I and II specified for "conventional C MEAs" in Reference 9 (see annotations in text above). 
the RH value from 1.00 to 0.25 does not directly lead to a change of the COR current as suggested by Equation 1 (viz., by $0.25^{0}, 0.25^{1}$, and $0.25^{2}$ for $\gamma_{\mathrm{COR}}=0,1$, and 2, respectively), is due to i) the $\mathrm{RH}$ dependence of the reversible potential of the various reactions, and ii) the increasing proton conduction resistance of the membrane and the ionomer in the electrode with decreasing RH. The lower panels in Figure 1 clearly show that in all of the here investigated cases the vast majority of $\mathrm{I}_{\mathrm{SUSD}}$ is contributed by the COR (i.e., $\chi_{\mathrm{COR}} \approx 1$ ); even if at an assumed reaction order of $\gamma_{\mathrm{COR}}=2$ and at $\mathrm{RH}=0.25$, the $\chi_{\mathrm{COR}} \approx 0.95$ (substantially lower values of $\chi_{\mathrm{COR}}$ are typically only obtained for graphitized carbon supports, where a larger fraction of I $\mathrm{IUSD}_{\mathrm{S}}$ is carried by the oxygen evolution reaction). ${ }^{9}$ For the following comparison of experimental SUSD data and the calculated COR current densities depicted in Figure 1, an averaged value over the relative gas front position $\tau$ is reported, obtained by integrating the curves shown in Figure 1 (indicated by the area below each curve; for further explanations, see Reference 9).

\section{Experimental Results and Discussion}

Impact of electrode properties on SUSD degradation.-One of the simplifying assumptions in the employed SUSD model is neglecting any influences from capacitive currents during SUSD. While electrode capacitance in general cannot be neglected during SUSD with very short $\mathrm{H}_{2} /$ air anode $_{\text {gas }}$ gront residence times, ${ }^{16}$ the latter was kept constant at $1.3 \mathrm{~s}$ in the present study (approximately an order of magnitude higher than under automotive conditions). ${ }^{29}$ The subsequent paragraphs show that neglecting capacitive effects for such long residence times is justified, by proving that the time constant correlated with charging/discharging the cathode electrode capacitance is negligibly small compared to the $\mathrm{H}_{2} /$ air ${ }_{\text {anode }}$ gas front residence time.

The time constant $t_{R C}$ of charging/discharging the cathode electrode capacitively is given by

$$
\mathrm{t}_{\mathrm{RC}}=\mathrm{HFR} \cdot \mathrm{C}_{\text {cathode }}
$$

where HFR denotes the high frequency resistance of the cell at the relevant conditions and $\mathrm{C}_{\text {cathode }}$ is the cathode electrode capacitance. First, $\mathrm{C}_{\text {cathode }}$ can be estimated from a cyclic voltammogram recorded at the relevant SUSD conditions (see Figure 2). In order to receive the (geometric) electrode capacitance, the recorded currents were corrected for the oxidation of crossover hydrogen, which was determined by extrapolating linear sweep voltammetry responses recorded between $0.25-0.50 \mathrm{~V}_{\mathrm{RHE}}$ to $0 \mathrm{~V}_{\mathrm{RHE}}$ and divided by the applied potential scan rate $\left(20 \mathrm{mV} \cdot \mathrm{s}^{-1}\right)$. From Figure 2 it is obvious that both (hydr-)oxide formation and reduction region of the carbon supported Pt voltammogram are shifted toward more positive potentials for low $\mathrm{RH}(\mathrm{RH}=0.25)$, compared to the values observed at full humidification $(\mathrm{RH}=1.00)$ while the hydrogen region at potentials $\mathrm{E}<0.3 \mathrm{~V}_{\mathrm{RHE}}$ is rather unaffected. This reproduces consistently what already was reported before. ${ }^{30}$ The cathode potential is shifted from values close

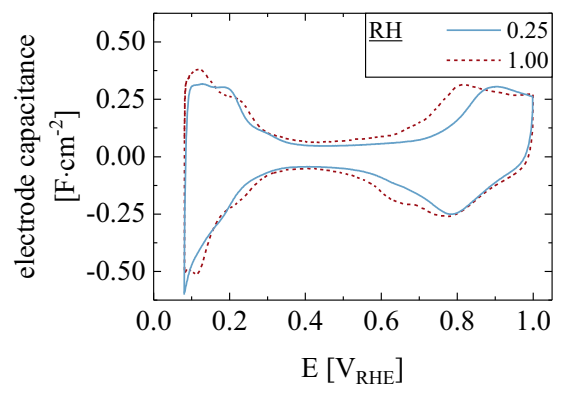

Figure 2. Cyclic voltammogram of a Gore Primea Mesga A510.1/ $\mathrm{M} 715.18 / \mathrm{C} 580.4 \mathrm{MEA}$ recorded at $20 \mathrm{mV} \cdot \mathrm{s}^{-1}, 80^{\circ} \mathrm{C}, 200 \mathrm{nccm} \mathrm{H} / 50 \mathrm{nccm}$ $\mathrm{N}_{2}$, p pry gas $=101 \mathrm{kPa}_{\text {inlet,abs }}, \mathrm{H}_{2}$ crossover corrected (determined by extrapolation of linear sweep voltammogram recorded at $1 \mathrm{mV} \cdot \mathrm{s}^{-1}$ between 0.25 $0.50 \mathrm{~V}_{\mathrm{RHE}}$ to $\left.0.00 \mathrm{~V}_{\mathrm{RHE}}\right)$. to $\approx 1.0 \mathrm{~V}_{\mathrm{RHE}}$ to values around $\approx 1.6 \mathrm{~V}_{\mathrm{RHE}}$ during an SUSD event, thus the electrode capacitance in this potential region needs to be considered. However, it is experimentally difficult to assess the electrode capacitance without i) recording faradaic offset currents stemming from carbon oxidation and oxygen evolution reaction, and ii) corroding the electrode under study to an undesirable amount. Thus, one can, at best, assume $\mathrm{C}_{\text {cathode }}$ to stay constant at potentials $\geq 1.0 \mathrm{~V}_{\mathrm{RHE}} \cdot{ }^{16} \mathrm{At}$ $1.0 \mathrm{~V}_{\mathrm{RHE}}, \mathrm{C}_{\text {cathode }}$ is approximately the same for high and low $\mathrm{RH}$, at a value of $\approx 0.25 \mathrm{~F} \cdot \mathrm{cm}^{-2}$, which will further be used for the estimation of the time constant for the CCMs used in this study.

Second, the HFR (high frequency resistance) of the employed PEMFC MEA and hardware needs to be assessed. Figure 3 shows a comparison of the values obtained with the utilized model parameters, ${ }^{9}$ and experimentally recorded values.

$$
\mathrm{HFR}=\frac{18 \mu \mathrm{m}}{\sigma \cdot \mathrm{RH}^{\gamma \text { membrane }}}+0.02 \Omega \cdot \mathrm{cm}^{2}
$$

Equation 4 represents a previously used analytical expression for the HFR as a function of RH at constant membrane thickness $\left(t_{\text {mem }}\right)$ of $18 \mu \mathrm{m}$ and an electrical contact resistance of the utilized flowfields and gas diffusion layers of $0.02 \Omega \cdot \mathrm{cm} .{ }^{29}$ While the original model by Gu et al. reports values of $88.1 \mathrm{mS} \cdot \mathrm{cm}^{-1}$ for $\sigma$ (membrane proton conductivity) 1.84 for $\gamma_{\text {membrane }}$ (effective reaction order), the values obtained here from fitting our experimental data are $\sigma=108$ $\mathrm{mS} \cdot \mathrm{cm}^{-1}$ and $\gamma_{\text {membrane }}=1.98$. As is shown in Figure 3 , both our fitting parameters and those by $\mathrm{Gu}$ et al. provide an equally good fit (see solid vs. dashed lines, respectively) with the experimental data (symbols). With the measured HFR values and the above estimated value of $\mathrm{C}_{\text {cathode }} \approx 0.25 \mathrm{~F} \cdot \mathrm{cm}^{-2}$, the resulting $\mathrm{t}_{\mathrm{RC}}$ values range from $\approx 0.01-0.10 \mathrm{~s}$ (see Equation 3 ). Considering that after a period of $3 \cdot t_{\mathrm{RC}}$, the capacitive current of an R-C circuit has decayed by $\approx 95 \%$, one can neglect capacitive contributions at time scales $>0.03-0.30$ $\mathrm{s}$, depending on RH. With the $1.3 \mathrm{~s}$ residence time applied in the present study, this is fulfilled in all cases, while furthermore being short enough to avoid depletion of the reactants in the anode flowfield, which was reported to occur at $\mathrm{H}_{2} /$ air anode $_{\text {and }}$ residence times $>3$ $\mathrm{s} .{ }^{10}$ It is noteworthy that $t_{\mathrm{RC}}$ is also negligibly small compared to the timescale used in the potentiostatic COR experiments performed in this study, rendering the fit of recorded mass spectrometric currents over a time scale of $30 \mathrm{~s}$ suitable without further corrections (see section about COR experiments below).

Performance decay during $\boldsymbol{S U S D}$ cycles.-Figure 4 shows $\mathrm{H}_{2}$ /air ( $\mathrm{s}=1.5 / 1.8)$ polarization curves at $80^{\circ} \mathrm{C} / \mathrm{RH}=0.66$ and an inlet pressure of $170 \mathrm{kPa}_{\mathrm{abs}}$ before and after 60 SUSD cycles which were conducted on $50 \mathrm{~cm}^{2}$ MEAs at various RH values at the same temperature. All measured polarization curves before SUSD cycling at various $\mathrm{RH}$ conditions are summarized in a single averaged curve (asterisks), with the error bars indicating their standard deviation, while

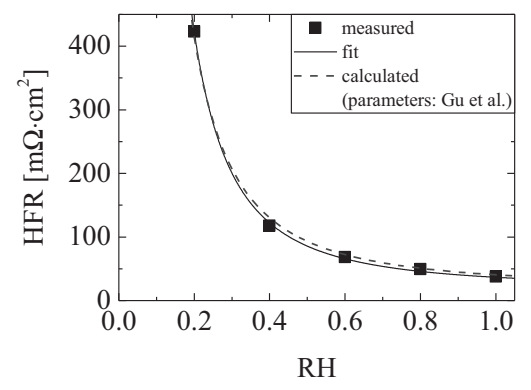

Figure 3. High frequency resistance (HFR) values versus $\mathrm{RH}$ for the Gore Primea Mesga MEA (18 $\mu \mathrm{m}$ membrane thickness) obtained at $80^{\circ} \mathrm{C}$ : ( experimental data; (-) fit according to Equation 4 using a contact resistance of $20 \mathrm{~m} \Omega \cdot \mathrm{cm} ;^{2}(--)$ calculation based on Equation 4 and the $\sigma$ and $\gamma_{\text {membrane }}$ values reported by Gu et al. ${ }^{17}$ The HFR values were determined from the real axis intercept of Nyquist plots, typically at $6-15 \mathrm{kHz}$ for $\mathrm{RH}=1.00-0.20$. 


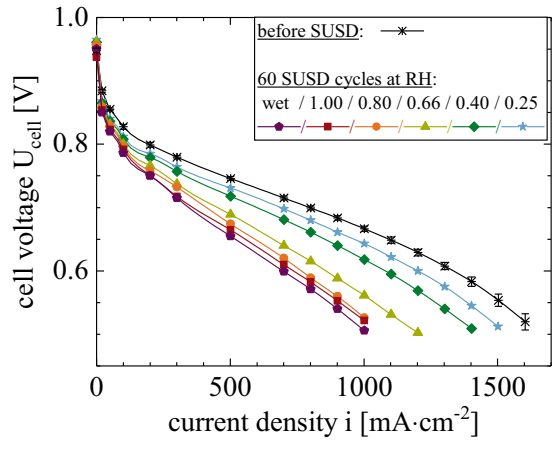

Figure 4. Polarization curves recorded before (asterisks) and after 60 SUSD cycles at the indicated RH (colors/lines defined in the figure), whereby "wet" denotes overhumidified gas at the inlet (with a nominal $\mathrm{RH}$ of 1.20). $\mathrm{H}_{2}$ /air polarization curve conditions: $\mathrm{T}_{\text {cell }}=80^{\circ} \mathrm{C}, \mathrm{RH}=0.66$, $\mathrm{p}_{\text {cell }}=170 \mathrm{kPa}_{\text {inlet,abs, }}$ stoichiometry $=1.5_{\mathrm{H} 2} / 1.8_{\text {air }}$. SUSD conditions: $\mathrm{T}_{\text {cell }}=80^{\circ} \mathrm{C}$, various $\mathrm{RH}$, $\mathrm{p}_{\text {dry gases }}=101 \mathrm{kPa}_{\text {inlet,abs }}, \mathrm{H}_{2}$ and air ${ }_{\text {anode }}$ flow rates through the anode flowfield as well as air flow rates through the cathode flow-field were all kept at $113 \mathrm{nccm}$, corresponding to a constant $\mathrm{H}_{2} / \mathrm{air}_{\text {anode }}$ front residence time of $\approx 1.3 \mathrm{~s}$ in all cases (note that $\mathrm{p}_{\text {cell }}$ in this case increases with increasing $\mathrm{RH}$ ).

the curves after 60 SUSD cycles at the indicated RH during SUSD cycling are shown individually. All polarization curves recorded after 60 SUSD cycles show lower cell voltages at a given current density compared to the initial performance. Clearly, this loss of cell voltage at a given current is more severe the higher the RH under which SUSD cycling was carried out. Although this also holds true for high RH values ( $\geq 0.80$; dark red, red, and orange lines), the observed differences are rather small. As would be expected for cathode carbon support induced performance losses, the loss of cell voltage is more severe at high current densities than at low ones. ${ }^{31}$ For example, at $\mathrm{RH}=1.00$ during SUSD, the cell voltage loss amounts to $\approx 50 \mathrm{mV}$ at $200 \mathrm{~mA} \cdot \mathrm{cm}^{-2}$ versus $\approx 120 \mathrm{mV}$ at $800 \mathrm{~mA} \cdot \mathrm{cm}^{-2}$.

The diagnostic polarization curves recorded after every set of 10 SUSD cycles on each MEA were evaluated to obtain $\mathrm{H}_{2} /$ air $_{\text {anode }}$ front residence time normalized degradation rates in the same way as described in our previous publication: ${ }^{9}$ as the voltage decays rather linearly with the number of SUSD cycles over the first $50 \mathrm{mV}$ performance loss at any current density, the number of SUSD cycles at a given current density $\left(200,800,1200\right.$ and $\left.1500 \mathrm{~mA} \cdot \mathrm{cm}^{-2}\right)$ was determined for a $50 \mathrm{mV}$ performance loss, which then was normalized by the $\mathrm{H}_{2} / \mathrm{air}_{\text {anode }}$ gas front residence time of $1.3 \mathrm{~s}$, yielding a specific SUSD degradation rate in units of $\mathrm{mV} \cdot \mathrm{cycle}^{-1} \cdot \mathrm{s}^{-1}$ for each current density.

Figure 5 displays the model predicted COR current densities as function of RH according to the utilized SUSD model, assuming various COR reaction orders $\gamma_{\text {COR }}$ with respect to RH (lines in Figure 5a). Furthermore, it shows the $\mathrm{H}_{2} / \mathrm{air}_{\text {anode }}$ front residence time normalized degradation rates determined from Figure 4 according to the above described procedure over the course of repeated SUSD cycles (symbols in Figure 5b; note that the data at $\mathrm{RH}=1,00$ are identical with those shown at $80^{\circ} \mathrm{C}$ in Figure 7 of our previous publication). ${ }^{9}$ Clearly, the experimental SUSD induced degradation rate is a strong function of RH. Independent of the current density of the $\mathrm{H}_{2} /$ air polarization curves, the SUSD degradation rate increases $\approx 3$-fold as the RH increases from $\mathrm{RH}=0.25$ to $\mathrm{RH}=1.00$. At high current densities, the degradation rate does not increase further upon overhumidifying the inlet gases during SUSD, indicating that the carbon corrosion leading to performance loss primarily at high current densities is not further promoted in the presence of liquid water compared to $\mathrm{RH}=1.00$. Kreitmeier et al..$^{14}$ reported an increase of the carbon loss rate during SUSD by a factor of 2 when increasing RH from 0.40 to 1.00 , which is quite consistent with the corresponding factor of SUSD degradation rates determined here in the same relative humidity range (see Figure $5 b$ ), demonstrating the linear relationship between carbon corrosion and SUSD performance loss (at least over the first $50 \mathrm{mV}$ of

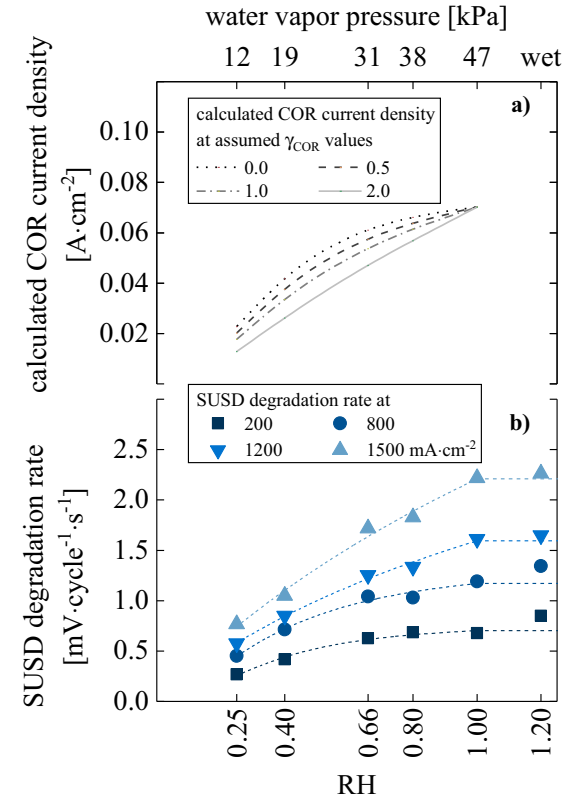

Figure 5. a) RH dependence of the model predicted COR current density for several assumed COR reaction orders with respect to $\mathrm{RH}\left(\gamma_{\mathrm{COR}}\right)$ and $\left.\mathrm{b}\right)$ experimentally determined SUSD induced degradation rates for SUSDs conducted at different RH ("wet" denotes over-humidified inlet gases at nominally RH = 1.20), evaluated over the initial $50 \mathrm{mV}$ performance loss at each current density and normalized to the $\mathrm{H}_{2} /$ air $_{\text {anode }}$ front residence time based on the data in Figure 4 (dashed lines are guide-to-the-eye). $\mathrm{H}_{2}$ /air polarization curve conditions: $\mathrm{T}_{\text {cell }}=80^{\circ} \mathrm{C}, \mathrm{RH}=0.66, \mathrm{p}_{\text {cell }}=170 \mathrm{kPa}_{\text {inlet,abs }}$, stoichiometry $=1.5_{\mathrm{H} 2} / 1.8_{\text {air }}$. SUSD conditions: $\mathrm{T}_{\text {cell }}=80^{\circ} \mathrm{C}$, various $\mathrm{RH}$, pdry gases $=101 \mathrm{kPa}_{\text {inlet,abs }}, \mathrm{H}_{2}$ and air ${ }_{\text {anode }}$ flow rates through the anode flow-field as well as air flow rates through the cathode flow-field were all kept at $113 \mathrm{nccm}$, corresponding to a constant $\mathrm{H}_{2} /$ air ${ }_{\text {anode }}$ front residence time of $\approx 1.3 \mathrm{~s}$ in all cases (note that $\mathrm{p}_{\text {cell }}$ in this case increases with increasing $\mathrm{RH}$ ).

performance loss). Therefore, it can be stated that in a real automotive system, the performance loss produced by a $\mathrm{H}_{2} / \mathrm{air}_{\text {anode }}$ front during start-up/shut-down is substantially lower when it occurs at low relative humidity.

Predicted COR current densities during SUSD conducted at $\mathrm{RH}=$ 0.25 compared to $\mathrm{RH}=1.00$ decrease by a factor of 3.1/3.5/4.0/5.4 for an assumed COR reaction order of $\gamma_{\mathrm{COR}}=0 / 0.5 / 1 / 2$. It should be noted that the strong decrease in the predicted COR rates with decreasing RH (see Figure 5a) is mostly due to the rapidly increasing HFR with decreasing RH (see Figure 3). With the exception of $\gamma_{\mathrm{COR}}=$ 2 , the trends of the experimental SUSD degradation rates and of the projected COR current densities versus $\mathrm{RH}$ are in reasonably good agreement. Keeping in mind that the model relies on several assumptions and simplifications, a distinct assignment of $\gamma_{\mathrm{COR}}$ by comparing the model data with experimental SUSD degradation rates is not feasible, as the relative differences are small $(<30 \%)$. Thus, $\gamma_{\mathrm{COR}}$ must be determined independently, which will be presented in the following section.

COR reaction order with respect to $R H$.- To experimentally determine $\gamma_{\mathrm{COR}}$, half-cell experiments were carried out, where the anode flow-field was kept under constant hydrogen flow $\left(5 \% \mathrm{H}_{2}\right.$ in $\left.\mathrm{N}_{2}\right)$, while a pure argon gas flow was applied to the cathode flow-field. The potential between the two flow-field plates was varied by means of a potentiostat from $0.50 \mathrm{~V}_{\mathrm{RHE}}$ to $1.50 \mathrm{~V}_{\mathrm{RHE}}$ in $30 \mathrm{~s}$ steps of $50 \mathrm{mV}$ each, as is shown in Figure 6 (note that the RHE scale is referenced here to $\mathrm{a}_{2}$ partial pressure of $101 \mathrm{kPa}$, i.e., the applied potential is corrected for the difference in $\mathrm{H}_{2}$ partial pressure using the Nernst equation). It should be noted that conventional carbon supports as used here exhibit a distinct dependence of the $\mathrm{COR}$ current $\left(\mathrm{i}_{\mathrm{COR}}\right)$ at any given potential 


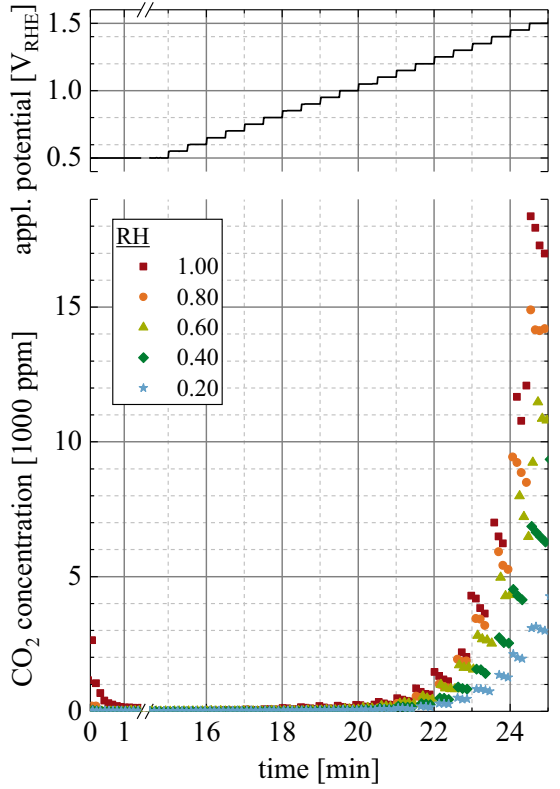

Figure 6. $\mathrm{CO}_{2}$ concentrations on a dry gas base at the cathode flow-field exhaust (lower panel) upon increasing the potential (referenced to RHE at $101 \mathrm{kPa} \mathrm{H}_{2}$ partial pressure) of the working electrode (electrode serving as cathode during normal fuel cell operation; upper panel) at $80^{\circ} \mathrm{C}$ and different $\mathrm{RH}$ values (specified in the figure legend). The $\mathrm{CO}_{2}$ data are determined from the $\mathrm{m} / \mathrm{z}=44$ mass spectrometer signal normalized to the $\mathrm{m} / \mathrm{z}=36$ signal of the ${ }^{36} \mathrm{Ar}$ isotope in the Ar carrier gas. The $\mathrm{CO}_{2}$ concentration data point density is reduced by $50 \%$ for better visibility (only every $2^{\text {nd }}$ data point shown here, while all recorded data points were used for further calculations). Conditions: $80^{\circ} \mathrm{C}, \mathrm{p}_{\text {dry }}=101 \mathrm{kPa}_{\text {inlet,abs }}, 200 \mathrm{nccm} 5 \% \mathrm{H}_{2}$ in $\mathrm{N}_{2}$ flowing through the anode flow-field (serving as reference/counter electrode) and 80 nccm Ar flowing through the cathode flow-field (serving as working electrode).

with the already occurred fraction of lost carbon mass $\left(\mathrm{w}_{\mathrm{loss}}\right):{ }^{19}$

$$
\mathrm{i}_{\mathrm{COR}} \propto\left(1-\mathrm{w}_{\text {loss }}\right)^{\mathrm{b}}
$$

where the exponent $b$ is a positive number. Two observations are apparent from Figure 6. First, the strong increase of the measured $\mathrm{CO}_{2}$ concentration in the PEMFC exhaust gas with increasing $\mathrm{RH}$ (almost an order of magnitude from $\mathrm{RH}=0.20$ to 1.00). And second, the time-dependent decay of the $\mathrm{CO}_{2}$ concentration at each individual potential step, consistent with the behavior described by Equation 5 . In the following paragraphs, the quantitative correlation between $\mathrm{i}_{\mathrm{COR}}$, $\mathrm{E}, \mathrm{RH}$, and $\mathrm{w}_{\text {loss }}$ will be examined.

From Figure 6, it is possible to convert the $\mathrm{CO}_{2}$ concentration values into a $\mathrm{COR}$ rate $\mathrm{i}_{\mathrm{COR}}^{\mathrm{m}}$ in units of $\mathrm{CO}_{2}$ current per gram of carbon support (i.e., in $\mathrm{A} \cdot \mathrm{g}_{\mathrm{C}}^{-1}$, assuming 4 electrons per evolved molecule $\mathrm{CO}_{2}$ ) via

$$
\mathrm{i}_{\mathrm{COR}}^{\mathrm{m}}=\mathrm{c}_{\mathrm{CO}_{2}} \cdot \frac{\dot{\mathrm{V}}_{\mathrm{Ar}}+\dot{\mathrm{V}}_{\mathrm{CO}_{2}}}{\mathrm{~V}_{0, \text { mol }}} \cdot \frac{4 \cdot \mathrm{F}}{\mathrm{l}_{\mathrm{C}} \cdot \mathrm{A}_{\text {active }}} \approx \mathrm{c}_{\mathrm{CO}_{2}} \cdot \frac{\dot{\mathrm{V}}_{\mathrm{Ar}}}{\mathrm{V}_{0, \text { mol }}} \cdot \frac{4 \cdot \mathrm{F}}{\mathrm{l}_{\mathrm{C}} \cdot \mathrm{A}_{\text {active }}}
$$

Here $\dot{\mathrm{V}}_{\mathrm{Ar}}$ and $\dot{\mathrm{V}}_{\mathrm{CO}_{2}}$ are the norm-volume flow rates (in norm $\mathrm{cm}^{3}$ per second) of $\mathrm{Ar}$ and $\mathrm{CO}_{2}$, respectively, $\mathrm{V}_{0 \text {,mol }}$ is the norm-volume of an ideal gas $\left(22.4 \cdot 10^{3} \mathrm{~cm}^{3} \cdot \mathrm{mol}^{-1}\right), \mathrm{l}_{\mathrm{C}}$ is the cathode carbon loading $\left(0.4 \cdot 10^{-3} \mathrm{~g}_{\mathrm{C}} \cdot \mathrm{cm}^{-2}\right), \mathrm{A}_{\text {active }}$ is the geometric MEA active area $\left(50 \mathrm{~cm}^{2}\right)$, and $\mathrm{F}$ is the Faraday constant $\left(96,485 \mathrm{~A} \cdot \mathrm{s} \cdot \mathrm{mol}^{-1}\right)$. The COR kinetics utilized in the SUSD model described above follow a Tafel-type equation, ${ }^{17}$ extended by a term accounting for the variation of $\mathrm{i}_{0, \mathrm{COR}}$ with $\mathrm{RH}$ (cf., Equation 1):

$\mathrm{i}_{\mathrm{COR}}^{\mathrm{m}}=\mathrm{i}_{00, \mathrm{COR}} \cdot \mathrm{RH}^{\gamma \mathrm{COR}} \cdot \mathrm{A}_{\mathrm{C}} \cdot\left(1-\mathrm{w}_{\mathrm{loss}}\right)^{\mathrm{b}} \cdot \exp \left[\left(\mathrm{E}-\mathrm{E}_{\mathrm{COR}}^{\mathrm{rev}}\right) \cdot \frac{\alpha \cdot \mathrm{F}}{\mathrm{R} \cdot \mathrm{T}}\right]$

Here, $\mathrm{i}_{00, \mathrm{COR}}$ is the exchange current density (in $\mathrm{A} \cdot \mathrm{m}_{\mathrm{C}}^{-2}$ ) at reference conditions $\left(80^{\circ} \mathrm{C}, \mathrm{RH}=1.00\right), \mathrm{A}_{\mathrm{C}}=800 \mathrm{~m}_{\mathrm{C}}^{2} \cdot \mathrm{g}_{\mathrm{C}}^{-1}$ is the specific

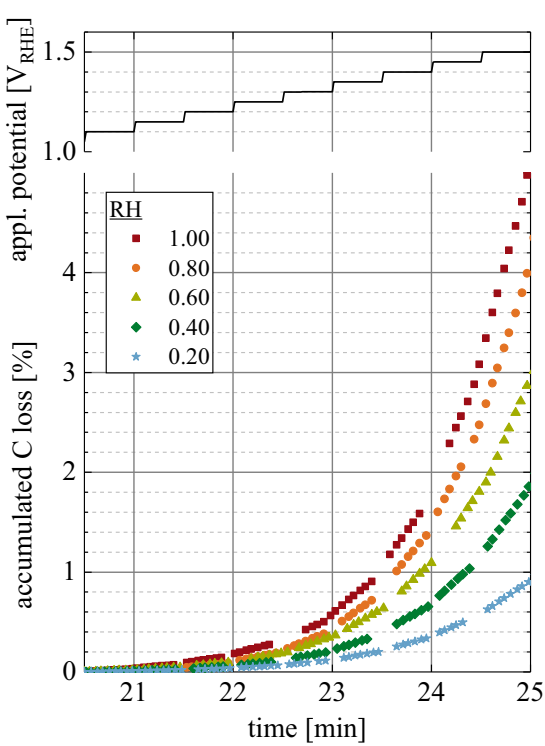

Figure 7. Accumulated carbon loss $\mathrm{w}_{\text {loss }}$ as calculated from the data given in Figure 6 using Equation 8.

surface area of the carbon used as cathode support, $\mathrm{E}_{\mathrm{COR}}^{\mathrm{rev}}$ is the reversible potential of the COR at each given condition (cf., our previous publication), ${ }^{9} \mathrm{R}$ is the universal gas constant $\left(8.314 \mathrm{~J} \cdot \mathrm{mol}^{-1} \cdot \mathrm{K}^{-1}\right)$, and $\mathrm{T}=353.15 \mathrm{~K}$ is the temperature at which experiments were conducted. By fitting Equation 7 to the independent variables $\mathrm{RH}, \mathrm{w}_{\text {loss }}$ and $\mathrm{E}$, it is possible to obtain the kinetic parameters $\mathrm{i}_{00, \mathrm{COR}}, \gamma_{\mathrm{COR}}$, $\mathrm{b}$, and $\alpha$. While $\mathrm{E}$ and $\mathrm{RH}$ are deliberately controlled quantities in the experiments and are therefore known, $\mathrm{w}_{\text {loss }}$ can be obtained by integrating $\mathrm{i}_{\mathrm{COR}}^{\mathrm{m}}$ over the time of the experiment (i.e., up to $\mathrm{t}_{\text {final }}=$ 25 min for each experimental data set):

$$
\mathrm{w}_{\text {loss }}(\mathrm{t})=\int_{\mathrm{t}^{\prime}=0}^{\mathrm{t}} \mathrm{dt}^{\prime} \frac{\mathrm{i}_{\mathrm{COR}}^{\mathrm{m}} \cdot \mathrm{M}_{\mathrm{C}}}{4 \cdot \mathrm{F}} \approx \sum_{\mathrm{j}=0}^{\mathrm{j} \max } \mathrm{c}_{\mathrm{CO}_{2}(\mathrm{j})} \cdot \frac{\dot{\mathrm{V}}_{\mathrm{Ar}}}{\mathrm{V}_{0, \text { mol }}} \cdot \frac{\mathrm{M}_{\mathrm{C}}}{\mathrm{l}_{\mathrm{C}} \cdot \mathrm{A}_{\text {active }}} \cdot \Delta \mathrm{t}_{\mathrm{j}}
$$

Here, $\mathrm{M}_{\mathrm{C}}$ is the molar mass of carbon $\left(12 \mathrm{~g} \cdot \mathrm{mol}^{-1}\right)$, and the integral was approximated via a sum of finite contributions: each data point $j$ recorded with the mass spectrometer was considered with its measured concentration $\mathrm{c}_{\mathrm{CO}_{2}(\mathrm{j})}$ and its period $\Delta \mathrm{t}_{\mathrm{j}}$ (between $2-3 \mathrm{~s}$ per point, up to the last recorded data point $j_{\max }$ ). The resulting trend of $\mathrm{w}_{\text {loss }}$ can be seen in Figure 7.

The SUSD model described above shows that the cathode potentials E during SUSD events cover a comparably narrow range, viz., from $\approx 1.3-1.5 \mathrm{~V}_{\mathrm{RHE}}$ (not shown). However, in order to obtain a reasonable fit of $\alpha$ and $\mathrm{i}_{00, \mathrm{COR}}$, it is necessary to use $\mathrm{i}_{\mathrm{COR}}$ data spanning as many orders of magnitude as possible, i.e., a range of $E$ as wide as possible. Therefore, for our kinetic study we utilize a potential window from $1.1 \mathrm{~V}_{\mathrm{RHE}}$ (with our lowest measured value of $\mathrm{i}_{\mathrm{COR}}^{\mathrm{m}} \approx$ $0.08 \mathrm{~A} \cdot \mathrm{g}_{\mathrm{C}}^{-1}$ at $\mathrm{RH}=0.20$ ) to $1.5 \mathrm{~V}_{\mathrm{RHE}}$ (with our highest measured value of $\mathrm{i}_{\mathrm{COR}}^{\mathrm{m}} \approx 23 \mathrm{~A} \cdot \mathrm{g}_{\mathrm{C}}^{-1}$ at $\mathrm{RH}=1.00$ ), covering more than two orders of magnitude of $\mathrm{i}_{\mathrm{COR}}^{\mathrm{m}}$ while spanning the potential range representative for conditions during SUSD. Fitting the data obtained from Figure 6, Equation 6, and Figure 7 simultaneously to Equation 7 in the range $1.1 \mathrm{~V}_{\mathrm{RHE}} \leq \mathrm{E} \leq 1.5 \mathrm{~V}_{\mathrm{RHE}}$ by a least-squares regression yields the kinetic parameters summarized in the right-most column of Table II; for comparison, the kinetic parameters published by $\mathrm{Gu}$ et al. ${ }^{17}$ which were used for Figure 1 and Figure $5 \mathrm{a}$ are also listed in Table II.

Quite surprisingly, $\mathrm{i}_{00}$ for the here conducted measurements is more than five orders of magnitude higher compared to the value published by Gu et al., ${ }^{17}$ which was used for the above described SUSD model (see Table II). For the COR in general, $\mathrm{i}_{00}$ carries a large uncertainty, as the typical lower limit for quantifying $\mathrm{i}_{\mathrm{COR}}^{\mathrm{m}}$ ranges between $10^{-1} \mathrm{~A} \cdot \mathrm{g}_{\mathrm{C}}^{-1}$ 
Table II. Kinetic parameters of Equation 7 used for the SUSD model described above (Gu et al. $)^{17}$ and parameter set obtained by evaluating the COR data measured in this study, both referenced to $80^{\circ} \mathrm{C}$. The errors given refer to the standard errors of the least-squares regression.

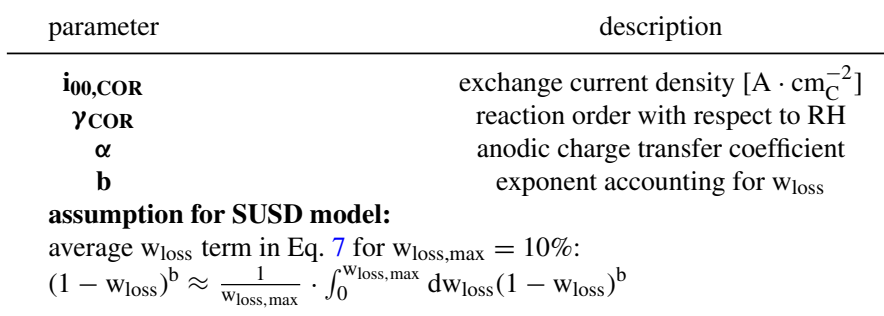

(this study) to $10^{-3} \mathrm{~A} \cdot \mathrm{g}_{\mathrm{C}}^{-1}$ (e.g., Yu et al.), ${ }^{10,19,32}$ while the value of $\mathrm{i}_{00}$ is $\approx 10$ (our study) to $\approx 15$ (Gu et al. $)^{17}$ orders of magnitude lower. Because of this, extrapolation of experimental data needs to be done over many orders of magnitude in order to obtain a value for $i_{00}$, so that the resulting $\mathrm{i}_{00}$ value strongly depends on the value of $\alpha$ (i.e., on the Tafel slope TS $\left.\equiv 2.303 \cdot \mathrm{R} \cdot \mathrm{T} \cdot \alpha^{-1} \cdot \mathrm{F}^{-1}\right)$. In our study, $\alpha$ is $\approx 45 \%$ lower $\left(\alpha=0.362\right.$ or $\mathrm{TS}=194 \mathrm{mV}$ at $\left.80^{\circ} \mathrm{C}\right)$ than the value presented by Gu et al. $\left(\alpha=0.67 \text { or TS }=105 \mathrm{mV} \text { at } 80^{\circ} \mathrm{C}\right)^{17}$ and $\approx 30 \%$ lower than the value reported by Mathias et al. $(\alpha=0.477$ or TS $=150 \mathrm{mV}$ at $\left.80^{\circ} \mathrm{C}\right) .{ }^{33}$ Despite this large variation in $\mathrm{i}_{00}$ values and Tafel slopes, the resulting projected COR currents in the SUSD relevant potential range of $1.3-1.5 \mathrm{~V}_{\mathrm{RHE}}$ are within a factor of $\approx 3$, as is illustrated in Figure $8 \mathrm{c}$ for the two kinetic data sets listed in Table II.

It should be pointed out that low $\alpha$ values (corresponding to high Tafel slopes) are often ascribed to unassigned non-kinetic losses in the fuel cell literature. One potential reason for such losses could be insufficient reactant supply. Table III summarizes the absolute values of the measured molar $\mathrm{CO}_{2}$ evolution rate at $1.5 \mathrm{~V}_{\mathrm{RHE}}\left(\dot{\mathrm{n}}_{\mathrm{CO}_{2}}^{1.5 \mathrm{~V}} \mathrm{~V}_{\mathrm{RE}}\right)$ and of the experimentally set water vapor feed flux for each $\mathrm{RH}$ setting, which demonstrates the high water stoichiometry of $\geq 13$ based on the assumption that two $\mathrm{H}_{2} \mathrm{O}$ are required for the formation of one $\mathrm{CO}_{2}$ (i.e., $\mathrm{C}+2 \mathrm{H}_{2} \mathrm{O} \rightarrow \mathrm{CO}_{2}+4 \mathrm{H}^{+}+4 \mathrm{e}^{-}$), so that the water vapor concentration across the entire MEA area can be considered reasonably constant. Therefore, a lacking supply of $\mathrm{H}_{2} \mathrm{O}$ to drive the COR cannot be the explanation for a lower $\alpha$ in the present study compared to previous literature. ${ }^{10,17,33}$ It should be noted that $\mathrm{H}_{2} \mathrm{O}$ transport losses due to diffusion through the ionomer are unlikely,

$\begin{array}{cc}\text { Gu et al. } & \text { this study } \\ 1.03 \cdot 10^{-18} & 2.8 \pm 0.5 \cdot 10^{-13} \\ \text { not reported. } & 1.06 \pm 0.02 \\ 0.67 & 0.362 \pm 0.005 \\ 10.4 & 6.2 \pm 0.7\end{array}$

0.61

0.74

\begin{tabular}{|c|c|c|}
\hline \multicolumn{3}{|c|}{$\begin{array}{l}\text { Table III. Adjusted molar water vapor feed at an Ar flow rate of } \\
80 \mathrm{nccm} \text {, compared with the observed molar COR rate }\left(\dot{\mathrm{n}}_{\mathrm{COR}}^{\left.1.5 \mathrm{~V}_{\mathrm{RHE}}\right)}\right. \\
\text { measured at } 1.5 \mathrm{~V}_{\mathrm{RHE}} \text { and } 80^{\circ} \mathrm{C} \text {. }\end{array}$} \\
\hline $\mathrm{RH}$ & $\begin{array}{c}\mathrm{H}_{2} \mathrm{O} \text { feed } \\
{\left[\mathrm{mol} \cdot \mathrm{cm}^{-2} \cdot \mathrm{s}^{-1}\right]}\end{array}$ & $\begin{array}{c}\dot{\mathrm{n}}_{\mathrm{CO}_{2}}^{1.5 \mathrm{~V}_{\mathrm{RHE}}} \\
{\left[\mathrm{mol} \cdot \mathrm{cm}^{-2} \cdot \mathrm{s}^{-1}\right]}\end{array}$ \\
\hline 1.00 & $5.7 \cdot 10^{-7}$ & $2.1 \cdot 10^{-8}$ \\
\hline 0.80 & $4.6 \cdot 10^{-7}$ & $1.7 \cdot 10^{-8}$ \\
\hline 0.60 & $3.4 \cdot 10^{-7}$ & $1.3 \cdot 10^{-8}$ \\
\hline 0.40 & $2.3 \cdot 10^{-7}$ & $8.0 \cdot 10^{-9}$ \\
\hline 0.20 & $1.1 \cdot 10^{-7}$ & $3.7 \cdot 10^{-9}$ \\
\hline
\end{tabular}

due to the low current densities during COR experiments (in all cases $\leq 0.1 \mathrm{~A} / \mathrm{cm}^{2}$ ). Another difference to be considered is that the parameter $\mathrm{b}$ describing the decay of the COR rate with the loss of carbon is lower by $\approx 40 \%$ in our study compared to that by Gu et al., ${ }^{17}$ whereby the time scales and potential ranges in the cited literature studies are obviously different from our experiments (measurements over minutes to hours between $1.1-1.3 \mathrm{~V}_{\mathrm{RHE}}$ for the data set by $\mathrm{Gu}$ et al., ${ }^{17}$ in Table II (measured by Yu et al. ${ }^{10}$ versus seconds to minutes between $1.2-1.5 \mathrm{~V}_{\mathrm{RHE}}$ in our study). For the smaller b parameter in our study, it should be noted that the range of $\mathrm{w}_{\text {loss }}$ covered in previous studies by $\mathrm{GM}^{17,19}$ was $10 \%$ carbon, while in our study, it was only $1 \%$ (at $\mathrm{RH}=0.20$ ) to $5 \%$ (at $\mathrm{RH}=1.00$ ). The more narrow potential range and/or experimental errors at the low $\mathrm{CO}_{2}$ formation rates at $1.1 \mathrm{~V}$

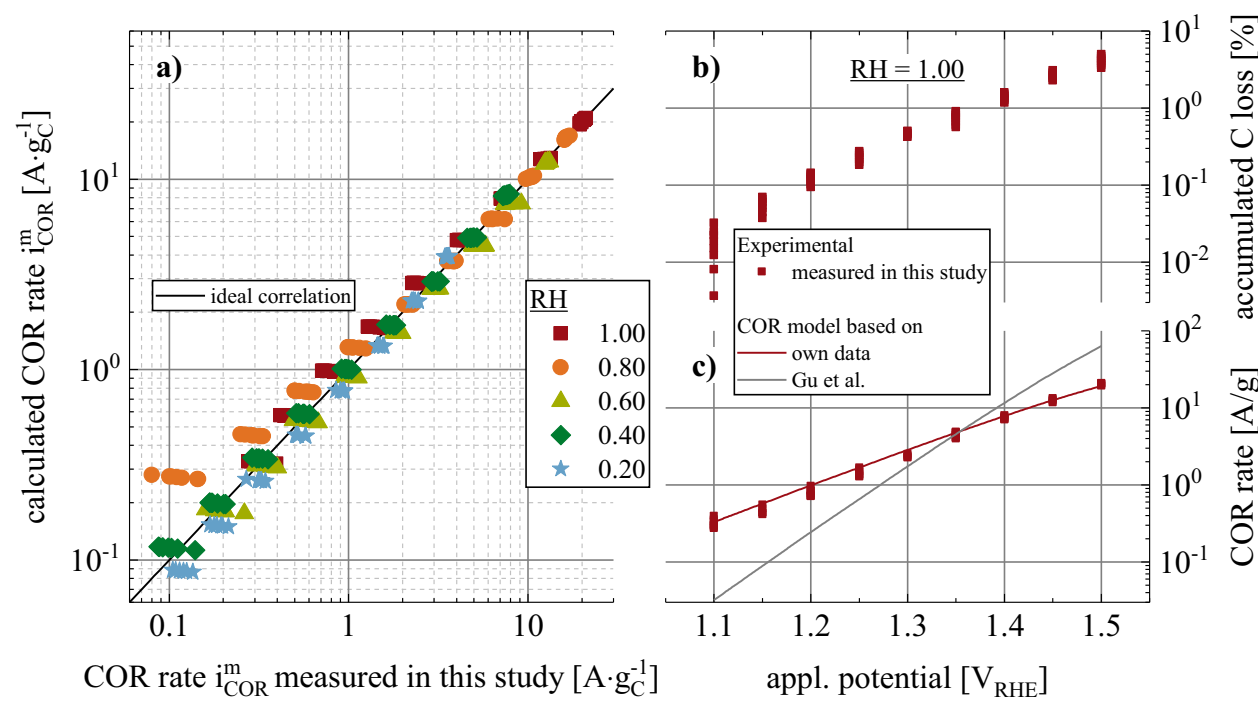

Figure 8. a) COR rate at $80^{\circ} \mathrm{C}$ and various RH (marked by the different symbols) calculated from Equation 7 using the kinetic parameters determined in this study (right-hand column of Table II) versus the experimentally determined COR rate at the same conditions (measured via $\mathrm{CO}_{2}$ evolution rates determined by mass spectrometry of Ar purged exhaust gas). b) Accumulated carbon loss at $\mathrm{RH}=1.00$ re-plotted from Figure 7. c) Experimentally determined $\mathrm{COR}$ rate at $80^{\circ} \mathrm{C}$ and $\mathrm{RH}=1.00$ (squares) and calculated COR rate at $\mathrm{RH}=1.00$ based on Equation 7, the kinetic data presented in this study (red line) or published by Gu et al. ${ }^{17}$ (gray line) and using the topmost data point of panel b) at each potential. 

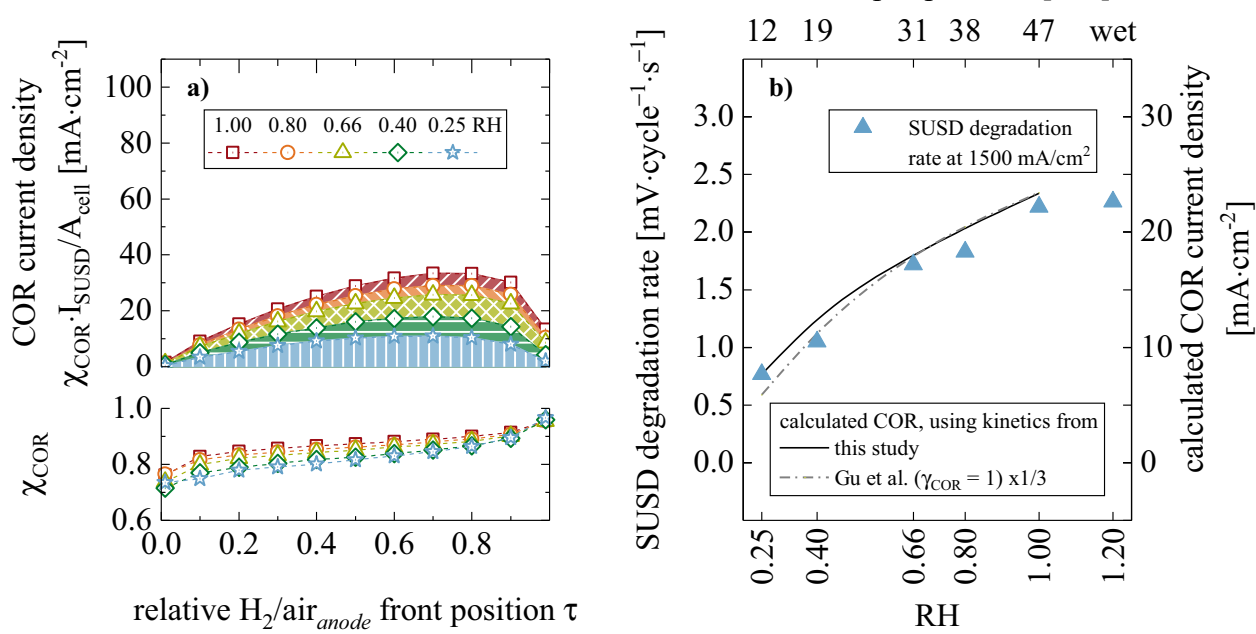

Figure 9. a) Re-calculation of the SUSD model predictions from Figure 1b with the COR kinetics measured in this study. Upper panel: Calculated carbon oxidation reaction (COR) current densities averaged over the cathode active area for SUSD events at relative humidities from $0.25-1.00$ (see legend in lower panels) versus relative $\mathrm{H}_{2}$ /air ${ }_{\text {anode }}$ front position ( $\tau=0$ means that the entire anode flow-field is filled with $\mathrm{H}_{2}$ ), utilizing a COR reaction order with respect to $\mathrm{RH}$ (see Equation 1) of $\chi_{\mathrm{COR}}=1$. Lower panel: Fractions of the SUSD current consumed by the COR $\left(\chi_{\mathrm{COR}}\right.$; see Equation 2$)$. Kinetic COR parameters as determined in this study (see Table II). b) RH dependence of the model predicted COR current density (right y-axis) for the COR kinetics determined in this study (full line) and from Gu et al. ${ }^{17}$ (dash-dotted line, identical to Figure 5a for $\gamma_{\mathrm{COR}}=1$, but divided by 3 ) as well as the experimentally determined SUSD induced degradation rates at $1500 \mathrm{~mA} \cdot \mathrm{cm}^{-2}$ for SUSDs conducted at different $\mathrm{RH}$ (triangles, identical to Figure $5 \mathrm{~b}$ ).

(see above) may be the cause for the large differences in $\alpha$ and TS values.

The $\mathrm{i}_{\mathrm{COR}}^{\mathrm{m}}$ values shown in Figure 8a (calculated via Equation 7 and using the parameter set shown in Table II) determined in this study (symbols as indicated in legend) are close to the (ideal) diagonal line, indicating a good quality of the performed fit. To compare the present kinetic parameters with the kinetic COR parameter set published by $\mathrm{Gu}$ et al., $\mathrm{i}_{\mathrm{COR}}^{\mathrm{m}}$ is calculated as function of potential and of $\mathrm{w}_{\text {loss }}$ via Equation 7. A parameter set for $\mathrm{w}_{\text {loss }}$, used for the calculations is determined from Figure $8 \mathrm{~b}$ (it re-plots the $\mathrm{w}_{\text {loss }}$ vs. potential data shown in Figure 7 at $\mathrm{RH}=1.00)$. In the experiments performed here, each potential was held for $30 \mathrm{~s}$ resulting in a gradually increasing accumulated carbon loss. This is reflected in the multiple data points at each potential in Figure 8b. In order to calculate COR rates utilizing Gu's model parameters and utilizing the kinetic parameters determined in this study for a direct comparison (both parameter sets shown in Table II), the topmost data point of $\mathrm{w}_{\text {loss }}$ at each potential shown in Figure $8 \mathrm{~b}$ is utilized. As already apparent from the above discussed difference in Tafel slopes, the projection based on the kinetic COR parameters published by $\mathrm{Gu}$ et al. ${ }^{16}$ does not follow the trend of the experimental COR rates measured here (cf., gray line vs. red squares). At $1.5 \mathrm{~V}_{\mathrm{RHE}}$, the currents projected with Gu's parameters are $\approx 3$-fold higher than currents projected with our data set. This is relevant to SUSD, since a potential $\mathrm{E} \approx 1.5 \mathrm{~V}_{\mathrm{RHE}}$ is expected to occur during SUSD on the cathode.

Because of the above described discrepancies in the COR kinetics published by $\mathrm{Gu}$ et al. and those determined in this study (cf., Table II), the initially shown SUSD model results were re-calculated using the parameter set for the COR determined in this study. In analogy to Figure 1, the predicted COR currents and the fractions $\chi_{\text {COR }}$ of the total SUSD current that go into the COR are shown in Figure 9a. Apparently, when using the COR kinetics determined in this study, the predicted COR current during SUSD at each $\mathrm{H}_{2} /$ air $_{\text {anode }}$ front position is $\approx 1 / 3$ of that predicted when using the data by $\mathrm{Gu}$ et al. ${ }^{17}$ (compare upper panels of Figure 9a and Figure 1b). Interestingly, the lower COR kinetics compared to Gu's data trigger a shift of $\chi_{\mathrm{COR}}$ toward lower values, while - also with the here determined COR kinetics in any predicted case - the fraction of SUSD current going into COR remains $>0.75$ (Figure 9a lower panel). Figure 9b shows the re-calculated SUSD model (full line), the SUSD model shown above (dash-dotted line from Figure 5a, but divided by 3 ) and, for reference, the experimentally determined SUSD degradation rates at $1500 \mathrm{~mA} \cdot \mathrm{cm}^{-2}$, as already shown in Figure $5 \mathrm{~b}$ (upward pointing triangles). Except for the $\approx 3$-fold difference in the COR current densities between the initially presented model (Figure 5a) and the model with here determined COR kinetics, the trend of the COR current density vs. RH is similar and, furthermore, in excellent qualitative agreement with the experimentally determined $\mathrm{RH}$ dependence of the SUSD degradation rates (a factor of $\approx 3$ between $\mathrm{RH}=0.25$ and $\mathrm{RH}=1.00$ ). While a conclusive explanation for the different COR kinetics reported by $\mathrm{Gu}$ et al. ${ }^{17}$ and those determined in this study cannot be given at this point, one experimental difference could be the exact carbon material used in each study (this study: high surface area carbon; further details proprietary to W. L. Gore GmbH). However, even considering the different values for the COR kinetic parameters $\mathrm{i}_{00}$ and $\alpha$, the relative trends of predicted SUSD currents using either parameter set allows for a good qualitative agreement with experimental data. This, together with the COR experiments carried out in this study, allows to establish that the COR reaction order with respect to $\mathrm{RH}$ is unity.

Implication of the temperature and $\mathrm{RH}$ dependence of the SUSD degradation rates.-Assuming that $\mathrm{RH}$ and temperature act independently on SUSD induced damage as well as considering our previous findings on the temperature dependence of the SUSD performance decay (cf., Equation 7 ), one would project an $\approx 40$-fold lower SUSD induced performance degradation at high current densities, when SUSD events with conventional high surface area carbon supported MEAs occur at low temperature and low $\mathrm{RH}\left(5^{\circ} \mathrm{C}, \mathrm{RH}=0.25\right)$ compared to the conventional reference conditions of high temperature and high $\mathrm{RH}\left(80^{\circ} \mathrm{C}, \mathrm{RH}=1.00\right)$. This can be seen in Figure 10 , where we combined data from our previous study on the temperature dependence of the SUSD degradation ${ }^{9}$ with the findings on the RH dependence of the SUSD degradation in the present study. It is noteworthy that a membrane and ionomer hydration corresponding to $\mathrm{RH}=0.25$ referenced to $5^{\circ} \mathrm{C}$ may be achieved in reality rather by a controlled drying procedure when shutting down a hot PEMFC stack from conditions of operation. As explained by Tajiri et al., ${ }^{34}$ this hydration state can 


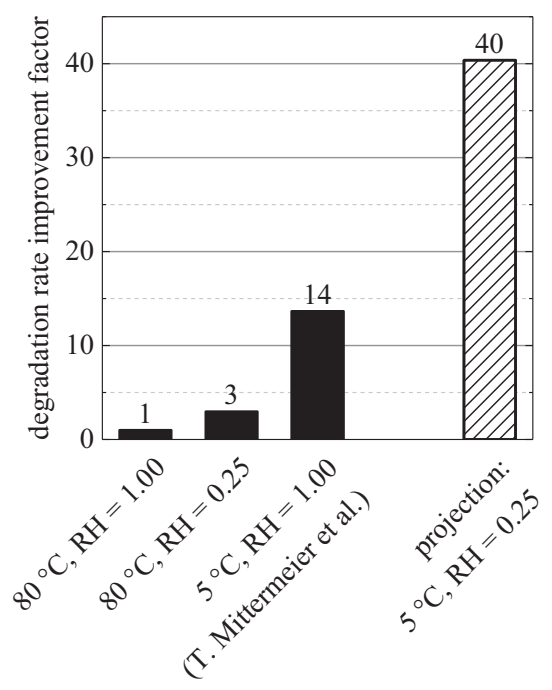

Figure 10. Improvement factor for SUSD degradation rates determined at $1500 \mathrm{~mA} \cdot \mathrm{cm}^{-2}$, measured with conventional high surface area carbon supports as function of temperature (T. Mittermeier et al. $)^{9}$ and as function of RH (this study). Projection based on multiplication of both effects.

be expected to stay almost constant when gas supply is shut off, leading to a situation equivalent to equilibrating the PEMFC at $5^{\circ} \mathrm{C}$ and $\mathrm{RH}=0.25$.

\section{Conclusions}

In this study, we demonstrate the significant impact of relative humidity ( $\mathrm{RH}$ ) during $\mathrm{H}_{2} /$ air $_{\text {anode }}$ front induced start-up/shut-down (SUSD) events on the performance degradation of PEMFCs via diagnostic polarization curves. For the employed membrane electrode assemblies (MEAs) with electrodes based on at Pt/C catalyst with a conventional high surface area carbon support, a factor of $\approx 3$ in lower SUSD induced performance decay rate (expressed as $\mathrm{mV} \cdot$ cycle $^{-1} \cdot \mathrm{s}^{-1}$ ) was found when reducing the relative humidity from $\mathrm{RH}=1.00$ to 0.25 at $80^{\circ} \mathrm{C}$ during SUSD events. This experimentally determined factor is rather consistent with literature data and in excellent agreement with our model predicted factor of $\approx 3$, after utilizing COR kinetics for the model, which were determined in the present study.

The carbon oxidation reaction order with respect to relative humidity $\left(\gamma_{\mathrm{COR}}\right)$ used in our model was experimentally determined in half-cell experiments with the same MEAs by on-line exhaust gas analysis, yielding a value of $\gamma_{\mathrm{COR}}=1$. Combining the results of the present study with previous results, ${ }^{9}$ one would project an $\approx 40$-fold lower SUSD induced performance degradation, when SUSD events with conventional high surface area carbon supported MEAs occur at low temperature and low $\mathrm{RH}\left(5^{\circ} \mathrm{C}, \mathrm{RH}=0.25\right)$ compared to the conventional reference conditions of high temperature and $\mathrm{RH}\left(80^{\circ} \mathrm{C}, \mathrm{RH}\right.$ $=1.00$ ). These findings underline the strong interaction between fuel cell operation conditions and degradation behavior of fuel cell materials. Therefore, an optimized interplay of fuel cell system engineers and material scientists is necessary in order to coherently adjust operation strategies and material selections for a successful commercial mass production of FCEVs.

\section{Acknowledgments}

Financial support by Volkswagen AG is gratefully acknowledged.

Parts of this work were published in T. M.'s doctoral thesis: T. Mittermeier, Proton Exchange Membrane Fuel Cells - Platinum-
Free Oxygen Reduction and Performance Degradation by StartUp/Shut-Down Events, Cuvillier, Göttingen, Germany (2018), ISBN 9783736997288

\section{ORCID}

Thomas Mittermeier (1D https://orcid.org/0000-0002-3286-4095

\section{References}

1. U.S. Department of Energy and U.S. Environmental Protection Agency, Compare Fuel Cell Vehicles, retrieved from https://www.fueleconomy.gov/feg/fcv_sbs.shtml, (accessed 10/11/2018).

2. B. K. Hong and S. H. Kim, ECS Trans., 86(13), 3 (2018).

3. A. Yamashita, M. Kondo, S. Goto, and N. Ogami, Development of High-Pressure Hydrogen Storage System for the Toyota "Mirai", SAE International, (2015).

4. Toyota Motor Sales USA Inc. (11/01/2016), [Updated] October 2016 Sales Chart [Press release], retrieved from http://corporatenews.pressroom. toyota.com/releases/tms-october-2016-sales-chart.htm, (11/20/2016).

5. U.S. Department of Energy, (2016), Fuel Cell Technologies Office MultiYear Research, Development, and Demonstration Plan, U.S. Department of Energy, retrieved from http://energy.gov/eere/fuelcells/downloads/ fuel-cell-technologies-office-multi-year-research-development-and- 22.

6. O. Gröger, H. A. Gasteiger, and J.-P. Suchsland, J. Electrochem. Soc., 162(14), A2605 (2015).

7. J. Kurtz, S. Sprik, C. Ainscough, and G. Saur, (2015), U.S. Department of Energy Annual Merit Review Proceedings Technology Validation - TV001, retrieved from https://www.hydrogen.energy.gov/annual_review15_validation.html, (02/26/2017).

8. C. A. Reiser, L. Bregoli, T. W. Patterson, J. S. Yi, J. D. Yang, M. L. Perry, and T. D. Jarvi, Electrochem. Solid-State Lett., 8(6), A273 (2005).

9. T. Mittermeier, A. Weiß, F. Hasché, G. Hübner, and H. A. Gasteiger, J. Electrochem. Soc., 164(2), F127 (2017).

10. P. T. Yu, W. Gu, J. Zhang, R. Makharia, F. T. Wagner, and H. A. Gasteiger, in Polymer Electrolyte Fuel Cell Durability, F. N. Büchi, M. Inaba, and T. J. Schmidt, eds., p. 29 Springer New York, (2009).

11. T. A. Greszler, G. M. Robb, J. P. Salvador, B. Lakshmanan, and H. Gasteiger, Shutdown Strategy to Avoid Carbon Corrosion Due to Slow Hydrogen/Air Intrusion Rates, Pat. US 8580445 B2, (2013).

12. M. L. Perry, T. Patterson, and C. Reiser, ECS Trans., 3(1), 783 (2006).

13. K. H. Lim, H.-S. Oh, S.-E. Jang, Y.-J. Ko, H.-J. Kim, and H. Kim, J. Power Sources, 193(2), 575 (2009).

14. S. Kreitmeier, A. Wokaun, and F. N. Büchi, J. Electrochem. Soc., 159(11), F787 (2012).

15. A. Ofstad, J. Davey, S. Sunde, and R. L. Borup, ECS Trans., 16(2), 1301 (2008).

16. W. Gu, R. N. Carter, P. T. Yu, and H. A. Gasteiger, ECS Trans., 11(1), 963 (2007).

17. W. Gu, P. T. Yu, R. N. Carter, R. Makharia, and H. A. Gasteiger, in Modern Aspects of Electrochemistry, vol. 49, U. Pasaogullari and C.-Y. Wang, eds., p. 45, Springer New York, (2010).

18. J. Zhang, H. A. Gasteiger, and W. Gu, J. Electrochem. Soc., 160(6), F616 (2013).

19. P. T. Yu, W. Gu, R. Makharia, F. T. Wagner, and H. A. Gasteiger, ECS Trans., 3(1), 797 (2006).

20. J. H. Kim, E. A. Cho, J. H. Jang, H. J. Kim, T. H. Lim, I. H. Oh, J. J. Ko, and S. C. Oh, J. Electrochem. Soc., 157(1), B104 (2010)

21. C. Simon, F. Hasché, and H. A. Gasteiger, J. Electrochem. Soc., 164(6), F591 (2017).

22. M. A. Modestino, D. K. Paul, S. Dishari, S. A. Petrina, F. I. Allen, M. A. Hickner, K. Karan, R. A. Segalman, and A. Z. Weber, Macromolecules, 46(3), 867 (2013).

23. A. Kusoglu, D. Kushner, D. K. Paul, K. Karan, M. A. Hickner, and A. Z. Weber, Adv Funct. Mater, 24(30), 4763 (2014).

24. H. Iden, K. Sato, A. Ohma, and K. Shinohara, J. Electrochem. Soc., 158(8), B987 (2011)

25. K. G. Gallagher and T. F. Fuller, PCCP, 11(48), 11557 (2009).

26. E. Brightman and G. Hinds, J. Power Sources, 267, 160 (2014).

27. A. J. Appleby, Corrosion, 43(7), 398 (1987).

28. S. Maass, F. Finsterwalder, G. Frank, R. Hartmann, and C. Merten, J. Power Sources, 176(2), 444 (2008)

29. P. T. Yu and F. T. Wagner, Method for Shutting Down a Fuel Cell System Using an Air Purge, Pat. US 2008/0003465 A1, (2008).

30. Y. Liu, M. W. Murphy, D. R. Baker, W. Gu, C. Ji, J. Jorne, and H. A. Gasteiger, J. Electrochem. Soc., 156(8), B970 (2009).

31. R. N. Carter, W. Gu, B. Brady, P. T. Yu, K. Subramanian, and H. A. Gasteiger, in Handbook of Fuel Cells - Fundamentals, Technology and Applications, W. Vielstich, A. Lamm, and H. A. Gasteiger, eds., Vol. 6: Advances in Electrocatalysis, Materials, Diagnostics and Durability: Part 2, p. 829, John Wiley \& Sons, Ltd., (2009).

32. P. T. Yu, Z. Liu, and R. Makharia, J. Electrochem. Soc., 160(6), F645 (2013).

33. M. F. Mathias, R. Makharia, H. A. Gasteiger, J. J. Conley, T. J. Fuller, C. J. Gittleman, S. S. Kocha, D. P. Miller, C. K. Mittelsteadt, and T. Xie, Electrochem. Soc. Interface, 14(3), 24 (2005)

34. K. Tajiri, Y. Tabuchi, and C.-Y. Wang, J. Electrochem. Soc., 154(2), B147 (2007). 